\title{
A Loja da Escola Gabriel: Um Projeto de Educação Financeira
}

\section{Mageri Rosa Ramos}

Escola Municipal Gabriel Gonçalves da Silva

Secretaria Municipal de Educação/Juiz de Fora

mageri@uol.com.br

\section{Marcílio Dias Henriques}

Instituto Estadual de Educação de Juiz de Fora

Secretaria Estadual de Educação/MG

mdhenriques@oi.com.br

\section{Resumo}

Este artigo apresenta uma experiência com um projeto envolvendo Educação Financeira, desenvolvido, inicialmente, em uma sala de aula de $6^{\circ}$ ano de uma escola pública municipal e, posteriormente, envolvendo as oito turmas do Ensino Fundamental do turno vespertino dessa mesma escola. Dentre os resultados do projeto, destaca-se a percepção da importância da abertura institucional e docente para a inserção de novas metodologias nas aulas de Matemática e de projetos interdisciplinares que permitam a realização de uma Educação Financeira Escolar necessária à formação dos estudantes em nossos dias.

Palavras-chave: Educação Financeira Escolar. Educação Matemática Crítica. Pedagogia de Projetos.

\section{The School Gabriel Store: A Financial Education Project}

\begin{abstract}
This paper presents an experience with a project involving Financial Education, developed initially in a 6th grade classroom of a public school and, later, involving eight classes of Elementary School of the afternoon period of that same school. Among the results of the project, highlights the importance of institutional and teaching opening for the insertion of new methodologies in mathematics classes and interdisciplinary projects that will bring about a School Financial Education necessary for the formation of students in our own day.
\end{abstract}

Keywords: School Financial Education. Critical Mathematics Education. Project Pedagogy.

\section{Algumas Inspirações}

Neste artigo, apresentamos um relato de experiência sobre um projeto que desenvolvemos em uma escola pública do município de Juiz de Fora, Minas Gerais.

A proposta surgiu de nossas reflexões e leituras sobre a Pedagogia de Projetos (cf. HERNÁNDEZ, 1998), associadas aos nossos pressupostos e objetivos comuns à educação 
matemática que praticamos, ligados às noções trazidas pelo Modelo dos Campos Semânticos (LINS, 2004) e pela Educação Matemática Crítica (SKOVSMOSE, 2001), que defendem, por exemplo, a não-neutralidade política no processo educacional (a questão das decisões), as legitimidades do conhecimento produzido pelos alunos e a autonomia crítica de professores e estudantes, que se expressam na caracterização freireana da relação educando-educador como "a reinvenção do ser humano no aprendizado de sua autonomia" (FREIRE, 1997, p.105).

Desta forma, ao pensar e ao realizar o projeto de Educação Financeira “A Loja da Escola Gabriel", fomos inspirados por tais pressupostos, pelos trabalhos de pesquisadores que estão investigando a inserção da Educação Financeira no ambiente escolar (cf. CAMPOS, 2012; LOSANO, 2013; SILVA e POWELL, 2013; VITAL, 2014) e por noções da Pedagogia de Projetos, que consiste, entre outras características, em proporcionar aos alunos o maior número possível de experiências para o seu envolvimento efetivo no processo pedagógico - possibilitando uma aprendizagem que vai muito além de um mero assimilar de informações - e em considerar que não se aprende somente na escola, mas também fora de seus limites, com os diversos elementos externos à sua organização espacial e curricular.

\section{Descrevendo as Etapas do Projeto}

Esse projeto começou a ser idealizado em agosto de 2014, em uma de nossas aulas de Matemática para uma turma de $6^{\circ}$ ano do Ensino Fundamental, quando percebemos que, ao propor uma tarefa de Educação Financeira, muitos estudantes daquela classe sequer conheciam as cédulas monetárias vigentes em nosso país, e outros tantos não conseguiam calcular o troco a receber, em uma simples compra do dia-a-dia, sem utilizar papel, caneta e as operações aritméticas convencionais.

Arquitetamos, então, o projeto de uma lojinha na sala de aula, na qual todos os alunos vivenciariam alternadamente as posições de vendedores e compradores. Os produtos vendidos seriam embalagens vazias, de variados formatos, e o dinheiro utilizado seriam réplicas das cédulas originais, mas em dimensões menores. Cada um dos alunos receberia R\$100,00 em notas de brinquedo e iriam às compras. E assim ocorreu naquela turma de $6^{\circ}$ ano. Os preços dos "produtos" variavam entre $R$ \$ 5,00 e $R$ \$ 80,00. As embalagens mais bonitas e elaboradas eram vendidas mais rapidamente, mesmo sendo as mais caras. Na função de vendedores, os alunos aprendiam a totalizar o valor das compras, a dar trocos e também a fazer embrulhos.

Os estudantes podiam escolher o que comprar, desde que o valor total das compras estivesse dentro do valor recebido. Trabalhamos a noção de dar troco completando a quantia gasta, o que foi novidade para a maioria dos alunos. Alguns destes relataram que, na escola, problemas de Matemática envolvendo troco eram sempre resolvidos utilizando a subtração escrita, pois não 
aprenderam a fazer de outra maneira. E afirmaram que, na conferência de trocos em compras cotidianas, o cálculo mental quase nunca é usado por eles.

Estas informações, referentes à atividade "dar troco", remetem-nos à importante relação das legitimidades dos significados produzidos pelos alunos - por exemplo, para as operações usadas no troco - com as funções da escola. Segundo Lins e Gimenez (1997), estas funções não deveriam ser outras senão conduzir a tematização dos significados da matemática da rua, proporcionar o desenvolvimento de novos significados (possivelmente matemáticos, ou seja, da escola) e garantir a coexistência de significados da escola e da rua, reconhecendo que estes são dois mundos diferentes nos quais vivem nossos alunos, ambos com sua organização e seus modos legítimos de produzir significados. Para explicar isto, Lins e Gimenez (1997) utilizam o exemplo do troco, afirmando que, tradicionalmente, a escola

[...] parte do princípio de que a essência do troco é a subtração do total pago (um número) menos o total a pagar (um número), e que a maneira de fazer a subtração é escrever um número embaixo do outro. Mas essa é uma suposição completamente errada. Entre numa loja onde não há aquelas caixas registradoras que fazem o troco automaticamente, e compre algo. Se a pessoa não fizer contas no papel - o que não é nenhum crime! -, e simplesmente for pegando o dinheiro para lhe dar, pergunte a ela, depois que o dinheiro estiver em sua mão, se ela sabe quanto tem ali. É provável que ela não saiba, e a explicação é simples: a atividade na qual ela se engajou foi a de "dar troco corretamente", e o procedimento usado foi "completar". [...] Ela não fez nenhuma subtração, e não há razão para que saiba o resultado de uma suposta subtração. (LINS e GIMENEZ, 1997, p.20)

A primeira etapa do projeto, desenvolvida em duas aulas de 50 minutos, fez-nos observar o quanto ignorávamos (e ainda ignoramos, em parte) como os alunos lidam com o dinheiro e, também, pensar que algumas das indesejáveis e inevitáveis consequências deste desconhecimento docente são agravadas pela falta de planejamento e de discussão curricular quanto à educação financeira escolar e sua relação com outros temas da matemática escolar e da matemática da rua.

$\mathrm{Na}$ turma do $6^{\circ}$ ano, as compras eram feitas, em sua maior parte, por impulso, sem a consideração da utilidade dos "produtos", ou seja, os alunos compravam sem qualquer reflexão ou planejamento, o que nos fez pensar sobre quais seriam os motivadores reais das decisões de consumo tomadas cotidianamente pelo cidadão comum.

Todos os alunos daquela turma participaram da atividade, mas percebemos que, apesar do entusiasmo inicial, logo eles estavam desmotivados em comprar e vender caixinhas vazias.

Percebendo esse desinteresse e considerando o potencial da atividade, pensamos em montar uma loja com produtos reais, o que inicialmente seria apenas para aquela turma. Mas, com o propósito de continuar observando as dificuldades discentes em lidar com dinheiro e, ainda, de estimular e valorizar alunos de outras turmas, que vivem em uma região muito carente de recursos, decidimos estender este projeto a todo o turno da tarde daquela escola, que era composto por oito 
turmas do Ensino Fundamental, envolvendo cerca de 200 estudantes. No entanto, para implementarmos esta nova etapa do projeto, necessitávamos de apoio financeiro e de disponibilidade de tempo de outras pessoas para o trabalho a realizar.

Levamos o projeto à direção e aos demais professores da escola. E com o apoio manifesto dos diretores e de vários professores, ampliamos o projeto para todas as turmas de $6^{\circ}, 7^{\circ}$ e $8^{\circ}$ anos e para as três turmas das Séries Iniciais.

Com professores, familiares e amigos envolvidos, angariamos vários produtos para a "Loja da Escola Gabriel". À medida que conseguíamos brindes e doações em dinheiro para a confecção de lanches para a "loja", refazíamos as contas para saber quanto em "dinheiro" poderíamos dar a cada um dos alunos e qual seria o preço de cada mercadoria, já que nosso objetivo era de que os preços fossem os mais baixos possíveis, e assim cada aluno poderia comprar um número maior de produtos. Finalmente, decidimos que cada aluno receberia $\mathrm{R} \$ 10,00$. Com o total aproximado de 200 alunos, deveríamos ter, no mínimo, $\mathrm{R} \$ 2000,00$ em mercadorias e, a partir disto, definiríamos o preço de cada uma delas.

A "loja" foi dividida em três setores: um balcão com lanches e duas mesas com brinquedos, acessórios, material escolar e utilidades em geral (ver Figura 1). Uma destas mesas seria destinada para os alunos das Séries Iniciais, e a outra, para os alunos das Séries Finais do Ensino Fundamental, pois as mercadorias foram separadas considerando a idade dos "consumidores". O balcão de lanches contou com cachorro-quente, suco, pipoca, entre outras guloseimas.

Figura 1 - Registros da segunda etapa da "Loja da Escola Gabriel"
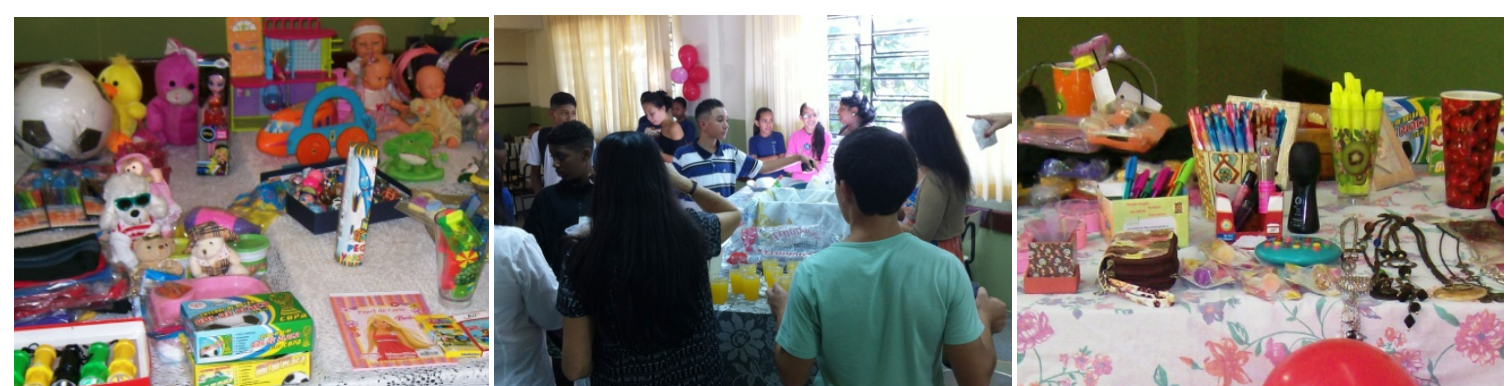

Fonte: Arquivo pessoal dos autores.

Precisávamos de um grande número de mercadorias e também de conter gastos. Como seriam necessárias muitas cédulas (réplicas), e comprá-las ou imprimi-las coloridas ficaria muito dispendioso, decidimos reproduzi-las em folhas de papel colorido, separando-as por valor. Notas de $\mathrm{R} \$ 1,00$ em folhas verdes, de $\mathrm{R} \$ 2,00$ em folhas azuis, etc. 
Funcionárias, professores e amigos nossos, sensibilizados com o projeto, deram suas contribuições, doando algum dinheiro ou seu trabalho. Um feirante, quando soube do motivo pelo qual comprávamos uma grande quantidade de tomates para o molho do cachorro-quente, doou parte deles. E assim, em mutirão, a segunda etapa do projeto foi tomando forma.

Nossa escola passava por um período instável em relação à violência no ambiente escolar, e esperávamos que este projeto pudesse também levar os alunos a entender o quanto eles são alvo de nossas atenções e, assim, se sentissem valorizados, minimizando a violência.

\section{Compras, Vendas e Novos Olhares Docentes}

No dia da realização da segunda etapa do projeto - que era uma surpresa para os alunos -, fomos a cada sala convidá-los para o evento e explicar o que iria acontecer, sem muitos detalhes, para que a surpresa não fosse anulada. Em uma das turmas, quando começamos a explanar, um aluno, que estava bastante agitado, disse em alto tom de voz: "Aposto que vai ser uma chatice!". Mas, por observarmos sua participação no projeto, percebemos que aquele estudante havia mudado de opinião.

Cada aluno recebeu R\$10,00 e todos foram convidados a ir às compras. As cédulas foram distribuídas de variadas formas, para facilitar o troco: uma nota de R \$10,00, ou duas notas de R\$ 5,00 , ou cinco notas de $\mathrm{R} \$ 2,00$, etc. Determinados alunos pediram para que trocássemos seu dinheiro recebido, porque queriam notas de cores diferentes. Outros meninos expressaram a sensação de estarem sendo desfavorecidos, ao observarem que alguns ganhavam mais notas que outros. Fez-se necessário explicar-lhes que todos recebiam o mesmo valor, apesar da diferença na quantidade de notas.

Os preços dos brindes variavam, em sua maioria, de $\mathrm{R} \$ 1,00$ a $\mathrm{R} \$ 3,00$. Alguns poucos produtos tinham preço diferente desses, sendo, no máximo, de R \$ 5,00. O cachorro-quente custou $\mathrm{R} \$ 2,00$, e os demais itens de lanche, $\mathrm{R} \$ 1,00$.

O projeto foi realizado no salão da escola, que não comportava todas as turmas concomitantemente. Por esta razão, recebemos primeiramente as turmas das Séries Iniciais, que tinham o horário antecipado para o intervalo do lanche, em relação às demais classes.

Quando os pequenos entraram e viram o salão decorado e com tantos produtos, a emoção comandou as compras. A primeira criança a entrar na "loja" avistou de imediato um brinquedo com o qual parecia sonhar: uma casinha da Polly (bonequinha da moda), que tinha balanço, escada, cômodos, etc. Ela nos estendeu todo seu dinheiro, agarrou a casinha e correu com seu brinde, sem perguntar se havia troco a receber ou se o dinheiro era suficiente para a compra. Foi necessário procurá-la para entregar o troco devido. 
Para que ninguém ficasse sem lanches ou brindes, estabelecemos uma única regra: todos deveriam gastar parte do dinheiro em lanches e parte em outros produtos. Naturalmente, alguns alunos não seguiram esta regra. Houve, por exemplo, quem comprasse cinco cachorros-quentes. Meninas das turmas de $7^{\circ}$ e $8^{\circ}$ anos não compraram lanches, mas somente pulseiras, anéis, esmaltes e outros acessórios femininos.

Alguns alunos agiram como se fosse uma situação real de compra, e pediram desconto ou reclamaram do preço das mercadorias. Outros disseram que era a primeira vez que tinham dinheiro para escolher o que comprar. Estes fatos nos remetem à questão da tomada de decisão quanto ao uso do dinheiro e ao consumo, assunto importante para a formação dos estudantes e pouco discutido em nossas aulas de Matemática.

A quantidade de brindes e lanches era suficiente para todos. Mas, como havia a possibilidade de escolha e alguns estudantes acabaram comprando somente brindes ou apenas lanches, a decisão de consumo de outros alunos foi afetada. Estes, temerosos de ficar sem os produtos que os interessavam, acabaram realizando suas compras rápida e impensadamente.

Outro exemplo dessa decisão de comprar atropeladamente foi o de dois irmãos gêmeos, alunos do $6^{\circ}$ ano. Eles adquiriram cinco lanterninhas cada um, ao preço de R\$ 2,00 a unidade. Quando lhes perguntamos, dias mais tarde, porque compraram tantas lanternas, eles nos responderam que gostaram muito das mesmas e ficaram com medo de que se esgotassem.

Observamos, na maioria dos alunos, uma real satisfação e um envolvimento efetivo com o projeto e com os elementos de Educação Financeira nele presentes. E, junto às turmas do Ensino Fundamental para as quais lecionamos, tivemos oportunidade de levantar discussões sobre tais elementos, relacionados a episódios observados durante o projeto.

A experiência de realização deste projeto nos permitiu perceber o quanto as instituições de ensino e os educadores podem fazer a diferença, ampliando suas metodologias, incluindo temáticas específicas na estrutura curricular e desenvolvendo projetos que possibilitem aos alunos aprender/adquirir autonomia para gerir suas finanças de modo consciente e, assim, influenciar positivamente o meio social e cultural em que estão inseridos, e não sendo por estes dominados, a ponto de ficarem à mercê dos sistemas financeiros, das campanhas publicitárias e das decisões político-econômicas dos governos.

\section{Referências}

CAMPOS, M. B. Educação financeira na matemática do ensino fundamental: uma análise da produção de significados. 2012. 150p. Dissertação (Mestrado Profissional em Educação Matemática). Universidade Federal de Juiz de Fora, Minas Gerais, 2012. 
FREIRE, P. Pedagogia da autonomia: saberes necessários à prática educativa. São Paulo: Paz e Terra, 1997.

HERNÁNDEZ, F. A Organização do Currículo por Projetos de Trabalho. Porto Alegre: Artes Médicas, 1998.

LINS, R. C. Matemática, monstros, significados e educação matemática. In: Bicudo, M.A.V. (Ed.).

Pesquisa em Educação Matemática: concepções e perspectivas. pp. 92-120. São Paulo: EDUNESP, 2004.

LINS, R. C.; GIMENEZ, J. Perspectivas em Aritmética a Álgebra para o Século XXI. Campinas: Papirus, 1997.

LOSANO, L. A. B. Design de tarefas de Educação financeira para o $6^{0}$ ano do ensino fundamental. 2013. 180p. Dissertação (Mestrado Profissional em Educação Matemática). Universidade Federal de Juiz de Fora, Minas Gerais, 2013.

SILVA, A. M. da; POWELL, A. B. Um programa de educação financeira para a matemática escolar da educação básica. Anais do XI ENEM - XI Encontro Nacional de Educação Matemática, Curitiba: SBEM, 2013.

SKOVSMOSE, O. Educação Matemática Crítica: A questão da democracia. Campinas: Papirus, 2001.

VITAL, M. C. Educação Financeira e Educação Matemática: inflação de preços. 2014. 199p. Dissertação (Mestrado Profissional em Educação Matemática). Universidade Federal de Juiz de Fora, Minas Gerais, 2014.

Submetido em janeiro de 2015 Aprovado em abril de 2015 